\title{
INFLUENCE OF USING DISCRETE CROSS-SECTION VARIABLES FOR ALL TYPES OF TRUSS STRUCTURAL OPTIMIZATION WITH DYNAMIC CONSTRAINTS FOR BUCKLING
}

\author{
Nenad Petrović ${ }^{1}$, Nenad Kostić $^{1}$, Nenad Marjanovićc ${ }^{1}$, Vesna Marjanović ${ }^{1}$ \\ ${ }^{1}$ Department of Mechanical Constructions and Mechanization, University of Kragujevac Faculty of \\ Engineering, Kragujevac, Serbia
}

\begin{abstract}
:
The use of continuous variables for cross-sectional dimensions in truss structural optimization gives solutions with a large number of different cross sections with specific dimensions which in practice would be expensive, or impossible to create. Even slight variations from optimal sizes can result in unstable structures which do not meet constraint criteria. This paper shows the influence of the use of discrete cross section sizes in optimization and compares results to continuous variable counterparts. In order to achieve the most practically applicable design solutions, Euler buckling dynamic constraints are added to all models. A typical space truss model from literature, which use continuous variables, is compared to the discrete variable models under the same conditions. The example model is optimized for minimal weight using sizing and all possible combinations of shape and topology optimizations with sizing.
\end{abstract}

ARTICLE HISTORY

Received: 20.04.2018.

Accepted: 12.06.2018.

Available: 30.06.2018.

\section{KEYWORDS}

Structural optimization, sizing, shape, topology, truss, Euler buckling, genetic algorithm

\section{INTRODUCTION}

Truss structural optimization is a complex process which if done correctly can result in directly applicable design solutions of favourable characteristics, compared to those which would be achieved through the use of conventional design methods. This process is very beneficial, as it can result in lighter, more rigid, and less expensive structures, while maintaining structural integrity, through optimizing different parameters. The formulation of the design problem needs to be as accurate to real-world applications as possible, while still being manageable for the optimization method used. In many truss optimization papers published to date, continuous sizing variables are still used. This presents a problem, as such a high accuracy of cross-sectional dimensions cannot be achieved in practice.
In order to have optimal results which meet all needed criteria, the same constraints must be used in optimization as are checked for in analytical approaches. These mainly consider static, or constant, constraints such as maximal allowed stress and maximal displacement at joints. As buckling constraints change in each iteration, they are considered dynamic constraints.

Many researchers in recent years have used various optimization methods to achieve optimal results without considering buckling constraints for different optimization types [1-4]. Bekdas et al. [5] used flower pollination algorithm to achieve competitive results in continuous sizing optimization, testing their algorithm on numerous standard truss problems.

Authors in [6] used continuous variables for truss sizing optimization on examples with 10, 17 and 25 bars with the added dynamic buckling constraint, showing the influence of the added 
constraint on optimal weight compared to work in [7], which did not consider buckling. In [8] researchers used continuous cross-sectional parameters for truss optimization of sizing, shape, topology and all their combinations.

Gonçalves et al. [9] have used discrete sizing variables with buckling constraints on 10,37 , and 20 bar truss examples in a few combinations of optimization types with great results. Hasancebi and K. Azad [10] developed an adaptive dimensional search algorithm specifically for discrete truss sizing optimization. Their research considers fixed slenderness ratios for tension and compression members as well as stress and displacement constraints. Discrete sizing optimization was proposed by Cheng et al. in [11], and tested on typical truss problems, however discrete variable sets were arbitrarily set to accommodate larger or smaller ranges in diameters. Researchers in [12] gave a comparison of the use of continuous and discrete sizing on a 10 bar truss example.

The goal of this research is to show the insignificant difference in resulting weight between discrete and continuous variables in truss crosssection optimization results. There is a big advantage to using discrete cross-sectional dimension variables, which is mainly reflected in practical application, and availability of stock sizes. The motivation behind this research is the need for achieving minimal weight design concepts which meet all real-world application criteria, thereby eliminating the need for extensive revision or adaptation of the optimal model.

\section{STRUCTURAL OPTIMIZATION PROBLEM}

Optimization is the process of finding solutions from a group of alternative possible solutions. These solutions necessitate better characteristics of the construction, while at the same time decreasing invested effort and expended costs [6]. Parametric truss structural optimization is an iterative process which is used to improve desired characteristics of a truss structure. The basic types of parametric optimization are sizing optimization, where cross-sectional parameters are considered variable, topology optimization, where the connections of nodes by bars are variable, and shape optimization, where, some or all coordinates, of, some or all nodes, are considered variable. By combining any two, or all three, of these optimization types simultaneously resulting structures can have more favourable characteristics, and take on designs which would not be possible through conventional engineering design methods.

Goal functions are generally minimal weight, price, stiffness, or some combination of those. This research will focus on minimizing weight, which is defined as follows:

$$
\left\{\begin{array}{l}
\min W(A)=\sum_{i=1}^{i=n} \rho_{i} A_{i} l_{i} \text { with } A=\left(A_{1}, \ldots, A_{n}\right) \\
\text { subjected to } \begin{cases}A_{\min } \leq A_{i} \leq A_{\max } & \text { for } i=1, \ldots, n \\
\sigma_{\min } \leq \sigma_{i} \leq \sigma_{\max } & \text { for } i=1, \ldots, n \\
u_{\min } \leq u_{j} \leq u_{\max } & \text { for } j=1, \ldots, k\end{cases}
\end{array}\right.
$$

where $n$ is the number of truss elements, $k$ is the number of nodes, $l_{i}$ is the length of the $i^{\text {th }}$ element, $A_{i}$ is the area of the $i^{t h}$ element cross section, $\sigma_{i}$ is the stress of the $i^{\text {th }}$ element, and $u_{j}$ is displacement of the $j^{\text {th }}$ node.

In addition to these standard constraints, in order to achieve a structure which is practically applicable and not subjected to buckling, the use of dynamic constraints for buckling are also used. The addition of this constraint increases the complexity of the optimization problem significantly. Since in the expression for Euler buckling (2) the same areas figure as denominators on both sides of the expression, the critical force load (3) can be used as the buckling constraint to minimize calculation. The constraint then is given as (4).

$$
\begin{aligned}
& \sigma_{A i}^{c o m p} \leq \sigma_{K i} \\
& \text { where } \sigma_{A i}^{c o m p}=\frac{F_{A i}^{c o m p}}{A_{i}} \text { and } \sigma_{K i}=\frac{F_{K i}}{A_{i}} \\
& F_{K i}=\frac{\pi^{2} \cdot E_{i} \cdot I_{i}}{l_{i}^{2}} \\
& \left|F_{A i}^{c o m p}\right| \leq F_{K i} \text { for } i=1, \ldots, n
\end{aligned}
$$

where $\sigma_{A i}$ is the axial compression stress, and $\sigma_{K i}$ is the critical buckling stress of the $i^{\text {th }}$ element. $F_{A i}{ }^{\text {comp }}$ is the axial compression force, $F_{K i}$ is Euler's critical load, $E_{i}$ is the modulus, and $l_{i}$ is the minimum area moment of inertia of the cross section of the of the $i^{\text {th }}$ element. The constraint from equation (4) is therefore added to the existing constraints in (1). For the purposes of this research Genetic algorithm (GA) is used. GA is a heuristic method for optimizing whose operation is based on mimicking natural processes [13]. Heuristic methods, such as $\mathrm{GA}$, are preferred for engineering problems due to their favourable characteristics. They have the 
ability to work with a large number of variables, overcoming local extremes, they have a high speed and efficiency of work, and a low threshold of needed facts about the problem in order to find a solution.

\section{EXAMPLE AND RESULTS}

For the purposes of this research sizing optimization as well as all possible combinations of structural optimization which consider crosssections as variables, will be compared in order to show the influence of the use of discrete variables as opposed to continuous variables on the results. The 25 bar space truss is commonly found in literature and was selected as the test example.

\subsection{Example formulation}

The 25 bar truss problem's bar and node layout is given in Fig.1. Truss elements are made from Aluminium 6063-T5 whose characteristics are: Young modulus $68947 \mathrm{MPa}$, and density of 2.7 $\mathrm{g} / \mathrm{cm}^{3}$. Force vectors in nodes are as follows: node $1(4.448,-44.48,-44.48) \mathrm{kN}$, node $2(0,-44.48$, 44.48) kN, node $3(2.224,0,0) \mathrm{kN}$, and node 6 $(2.6688,0,0) \mathrm{kN}$.

This space truss has cross sections of members grouped as follows: $1\left(A_{1}\right), 2\left(A_{2}-A_{5}\right), 3\left(A_{6}-A_{9}\right), 4$ $\left(A_{10}-A_{11}\right), 5\left(A_{12}-A_{13}\right), 6\left(A_{14}-A_{17}\right), 7\left(A_{18}-A_{21}\right), 8$ $\left(A_{22}-A_{25}\right)$. Optimization is limited with a tensile stress limit for all bar groups of $40 \mathrm{kN}$, and a maximal displacement of $\pm 0.00889 \mathrm{~m}$ for all nodes in all directions, and Euler buckling constraints for all bars.

For the optimization cases which consider shape, the following node coordinate constraints are used:

$$
\begin{aligned}
& 0,508 m \leq x_{4}, x_{5}, \quad-x_{3}, \quad-x_{6} \leq 1.524 m ; \\
& 1,016 m \leq y_{3}, y_{4}, \quad-y_{5}, \quad-y_{6} \leq 2,032 m ; \\
& 2,286 m \leq z_{3}, z_{4}, z_{5}, z_{6} \leq 3,302 m ; \\
& 1,016 m \leq x_{8}, x_{9},-x_{7}, \quad-x_{10} \leq 2,032 m ; \\
& 2,540 m \leq y_{7}, y_{8}, \quad-y_{9}, \quad-y_{10} \leq 3,556 m .
\end{aligned}
$$

Optimization types where topology is considered, can eliminate only entire groups of elements.

The continuous variable calculation has a minimal diameter limit of $1.433 \mathrm{~mm}$. The discrete set of variables for full round cross-section of Aluminium 6063-T5 was compiled with available standard dimensions from several vendors. There are 50 possible cross-section profiles diameters ranging from $12 \mathrm{~mm}\left(1.131 \mathrm{~cm}^{2}\right)$ to $356 \mathrm{~mm}$ $\left(995.382 \mathrm{~cm}^{2}\right)$. Namely diameters are: $12,16,20$, $25,30,34,35,40,45,55,60,65,70,75,80,85,90$, $95,100,105,110,115,120,125,130,140,145$, $150,152,160,165,170,175,178,180,190,200$, $210,220,230,240,250,254,260,270,278,280$, $300,305,356$, given in $\mathrm{mm}$.

The parametric model and optimization for this research were all done in an original software developed by the authors in Rhinoceros 5.0. This visually programmed software is based in Grasshopper, using Galapagos optimization, and Karamba plugins. The optimization method used is genetic algorithm due to availability.

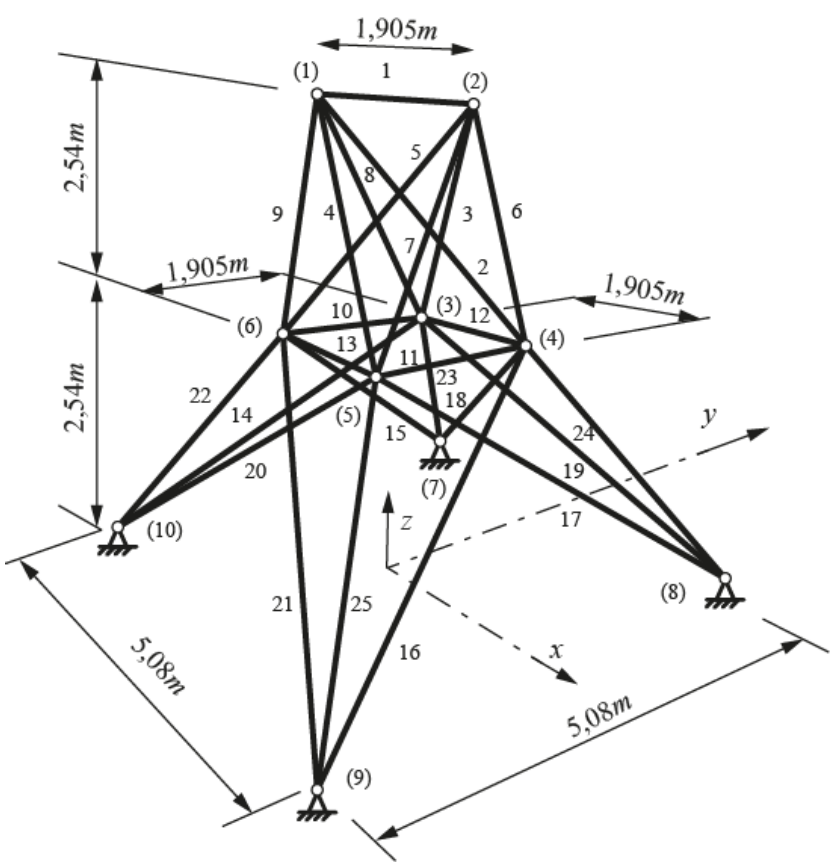

Fig. 1. 25 bar truss configuration

\subsection{Results}

Optimal results of just shape, just topology and their combination were not considered in this research as they do not take into account any change in cross-section dimensions. Table 1 gives node coordinates for optimization cases where shape is considered for continuous and discrete variable models separately. Resulting design concepts which use discrete cross-sectional variables are given in Fig. 2 .

Results of all optimization types, including cross-section areas by bar group, construction weight and maximal displacement are compared for both conrinuous and discrete cross-section parameters, and are given in Table 2. 


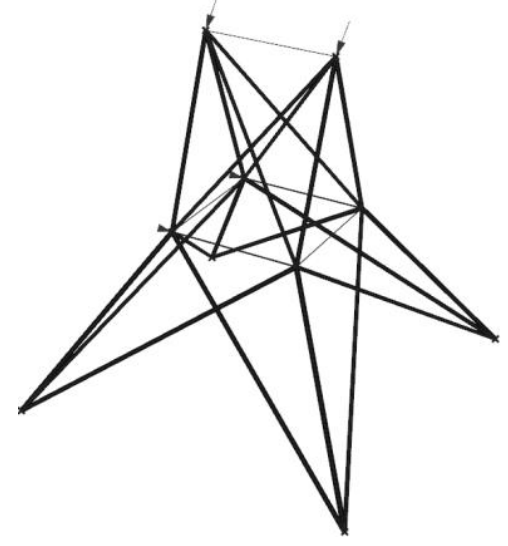

a)

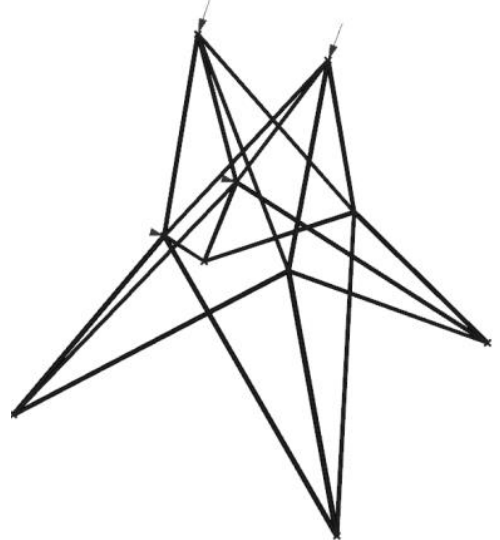

b)

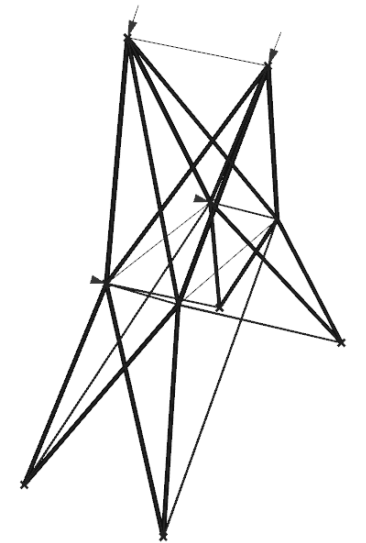

c)

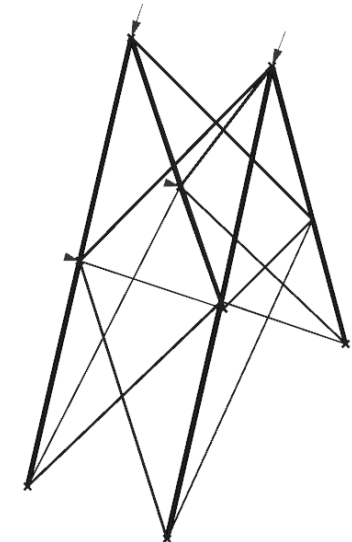

d)

Fig. 2. Optimal results using discrete sizing variables for a) sizing, b) sizing and topology, c) sizing and shape, and d) sizing, shape and topology optimization.
Table 1. Node coordinates according to variable and optimization type

\begin{tabular}{|c|c|c|c|}
\hline $\begin{array}{c}\text { Node } \\
\text { coordinate }\end{array}$ & $\begin{array}{c}\text { Variable } \\
\text { type }\end{array}$ & $\begin{array}{l}\text { Sizing } \\
\text { and } \\
\text { Shape }\end{array}$ & $\begin{array}{c}\text { Sizing, } \\
\text { Shape and } \\
\text { Topology }\end{array}$ \\
\hline \multirow{2}{*}{$\begin{array}{c}-X_{3}, X_{4}, X_{5},-X_{6} \\
{[\mathrm{~m}]}\end{array}$} & Cont. & 0.508 & 0.875 \\
\hline & Discr. & 0.508 & 0.995 \\
\hline \multirow{2}{*}{$\begin{array}{c}Y_{3}, Y_{4},-Y_{5},-Y_{6} \\
{[\mathrm{~m}]}\end{array}$} & Cont. & 1.342 & 1.228 \\
\hline & Discr. & 1.300 & 1.224 \\
\hline \multirow{2}{*}{$\begin{array}{c}\mathrm{Z}_{3}, \mathrm{Z}_{4}, \mathrm{Z}_{5}, \mathrm{Z}_{6} \\
{[\mathrm{~m}]}\end{array}$} & Cont. & 2.377 & 2.593 \\
\hline & Discr. & 2.460 & 2.590 \\
\hline \multirow{2}{*}{$\begin{array}{c}-\mathrm{X}_{7}, \mathrm{X}_{8}, \mathrm{X}_{9},-\mathrm{X}_{10} \\
{[\mathrm{~m}]}\end{array}$} & Cont. & 1.016 & 1.016 \\
\hline & Discr. & 1.016 & 1.016 \\
\hline \multirow{2}{*}{$\begin{array}{c}Y_{7}, Y_{8},-Y_{9},-Y_{10} \\
{[m]}\end{array}$} & Cont. & 2.540 & 2.540 \\
\hline & Discr. & 2.540 & 2.540 \\
\hline
\end{tabular}

\section{CONCLUSION}

Results obtained by using continuous variables give cross-section dimensions which are practically impossible to produce. Aside from this, the resulting structures have all, or almost all, different cross sections. Given that dimensional tolerances for cold formed profiles are rather high, the specific dimensions achieved through the use of continuous variables is impossible to produce. As these structures are usually at an optimum where even small divergences from their optimal dimensions result in an unstable structure, it can be concluded that the use of continuous crosssectional variables is unacceptable for practical application.

This paper gives a comparison of optimal results for all possible structural optimizations which consider cross-section dimensions as variables using discrete and continuous variables on the same example. Results show a difference of around $6 \%$, or $39.143 \mathrm{~kg}$, greater optimal weight for the sizing optimization using discrete variables from its continuous variable counterpart. For the sizing and topology combination the difference is around $3.2 \%$, or $21.085 \mathrm{~kg}$. The sizing and shape combination has about a $3.7 \%$, or $14.859 \mathrm{~kg}$, difference in optimal weight when using discrete variables. When optimizing the truss simultaneously for sizing, shape and topology, the difference is only around $0.57 \%$, or $1.865 \mathrm{~kg}$. These small differences are insignificant compared to the advantages of having an optimal model which can be practically applicable.

Further research in this field will include the limiting of the possible number of different crosssections used. 
Table 2. Comparison of bar cross-section group areas, displacements, and optimal weights for continuous and discrete optimization models.

\begin{tabular}{|c|c|c|c|c|c|c|c|c|}
\hline \multirow{2}{*}{$\begin{array}{c}\text { Element } \\
\text { group } \\
\text { area[cm }\end{array}$} & \multicolumn{2}{|c|}{ Sizing } & \multicolumn{2}{|c|}{ Sizing and Topology } & \multicolumn{2}{c|}{ Sizing and Shape } & \multicolumn{2}{c|}{$\begin{array}{c}\text { Sizing, topology and } \\
\text { shape }\end{array}$} \\
\cline { 2 - 9 } & Cont. & Discr. & Cont. & Discr. & Cont. & Discr. & Cont. & Discr. \\
\hline 1 & 0.0314 & 1.131 & 4.5240 & - & 1.3569 & 1.131 & 1.131 & - \\
\hline 2 & 0.126 & 23.758 & 24.630 & 23.758 & 23.118 & 23.758 & 12.117 & 12.566 \\
\hline 3 & 0.283 & 33.183 & 32.170 & 33.183 & 31.923 & 33.183 & 32.180 & 33.183 \\
\hline 4 & 0.503 & 2.011 & - & - & 1.131 & 1.131 & - & - \\
\hline 5 & 0.785 & 4.909 & - & 28.274 & 12.821 & 4.909 & - & - \\
\hline 6 & 1.131 & 28.274 & 28.274 & 28.274 & 6.432 & 7.069 & 3.558 & 4.909 \\
\hline 7 & 1.539 & 38.485 & 36.317 & 38.485 & 26.081 & 28.274 & 15.634 & 9.621 \\
\hline 8 & 2.011 & 44.179 & 40.715 & 44.179 & 27.392 & 28.274 & 34.586 & 38.485 \\
\hline Weight [kg] & 647.968 & 687.111 & 658.285 & 679.37 & 398.753 & 413.612 & 327.028 & 328.893 \\
\hline Displ. [m] & 0.0038 & 0.0035 & 0.0037 & 0.035 & 0.0021 & 0.0021 & 0.0026 & 0.0027 \\
\hline
\end{tabular}

\section{REFERENCES}

[1] K.S. Lee, Z.W. Geem, A new structural optimization method based on the harmony search algorithm. Computers \& Structures, 82 (9-10), 2004: 781-798.

https://doi.org/10.1016/j.compstruc.2004.01.002

[2] A. Kaveh, M. Ilchi Ghazaan, Hybridized optimization algorithms for design of trusses with multiple natural frequency constraints. Advances in Engineering Software, 79 (-), 2015: 137-147.

https://doi.org/10.1016/j.advengsoft.2014.10.001

[3] A. Mortazavi, V. Toğan, Sizing and layout design of truss structures under dynamic and static constraints with an integrated particle swarm optimization algorithm. Applied Soft Computing, $51(-), 2017$ : 239-252.

https://doi.org/10.1016/j.asoc.2016.11.032

[4] C.-Y. Wu, K.-Y. Tseng, Truss structure optimization using adaptive multi-population differential evolution. Structural and Multidisciplinary Optimization, 42 (4), 2010: 575-590.

https://doi.org/10.1007/s00158-010-0507-9

[5] G. Bekdaş, S.M. Nigdeli, X.-S. Yang, Sizing optimization of truss structures using flower pollination algorithm. Applied Soft Computing, $37(-)$, 2015: 322-331.

https://doi.org/10.1016/j.asoc.2015.08.037

[6] N. Petrovic, N. Marjanovic, N. Kostic, M. Blagojevic, M. Matejic, S. Troha, Effects of introducing dynamic constraints for buckling to truss sizing optimization problems. FME Transaction, 46 (1), 2018: 117-123.

https://doi.org/10.5937/fmet1801117P

[7] N. Petrovic, N. Marjanovic, N. Kostic, M. Blagojevic, M. Matejic, Sizing Optimization of
Parametrically Designed Trusses. $13^{\text {th }}$ International Conference on Accomplishments in Mechanical and Industrial Engineering"DEMI 2017", 2017, Banja Luka, Bosnia and Herzegovina, pp.93-100.

[8] N. Petrović, N. Kostić, N. Marjanović, Comparison of Approaches to 10 Bar Truss Structural Optimization With Included Buckling Constraints. Applied Engineering Letters, 2 (3), 2017: 98-103.

[9] M.S. Gonçalves, R.H. Lopez, L.F.F. Miguel, Search group algorithm: A new metaheuristic method for the optimization of truss structures. Computers \& Structures, $153(-)$, 2015: 165-184.

https://doi.org/10.1016/i.compstruc.2015.03.003

[10] O. Hasançebi, S.K. Azad, Adaptive dimensional search: A new metaheuristic algorithm for discrete truss sizing optimization. Computers \& Structures, 154 (-), 2015: 1-16.

https://doi.org/10.1016/i.compstruc.2015.03.014

[11] M.-Y. Cheng, D. Prayogo, Y.-W. Wu, M.M. Lukito, A Hybrid Harmony Search algorithm for discrete sizing optimization of truss structure. Automation in Construction, 69 (-), 2016: 21-33.

https://doi.org/10.1016/j.autcon.2016.05.023

[12] N. Petrović, N. Kostić, N. Marjanović, Discrete Variable Truss Structural Optimization Using Buckling Dynamic Constraints. Machine Design, 10 (2), 2018: 51-56.

https://doi.org/10.24867/MD.10.2018.2.51-5

[13] E.G. Shopova, N.G. Vaklieva-Bancheva, BASIC-A genetic algorithm for engineering problems solution. Computers \& Chemical Engineering, 30 (8), 2006: 1293-1309.

https://doi.org/10.1016/j.compchemeng.2006.03.003 


\section{ACKNOWLEDGEMENT}

This paper is a result of the TR32036 project, which is part of investigations of the Technological Development of Republic of Serbia. We would like to thank to the Ministry of Education, Science and Technological Development of the Republic of Serbia for their financial support during this investigation. 